\title{
Patterns of injuries to children on public playgrounds
}

\author{
Alison Mott, Rupert Evans, Kim Rolfe, David Potter, K W Kemp, J R Sibert
}

\begin{abstract}
The incidence and pattern of injuries to children in public playgrounds presenting to the accident and emergency department were reviewed over two six month summer periods in Cardiff. A total of 178 children (mean age 7.5 years) attended with a playground injury representing $1 \cdot 1 \%$ of all the children attending. One hundred and five children fell from equipment, of which the commonest was the climbing frame; 125 children had playground surface related injuries, 86 on bark and 30 on concrete. The pattern of injuries on the playground surfaces was different: fractures and sprains were more common on bark surfaces and lacerations and abrasions on concrete surfaces. Comparison of total injury rates showed there were fewer injuries on modernised playgrounds than expected but these differences were not significant. Modernised playgrounds are more popular, have new exciting equipment, and offer good play opportunities for children. However, the high fracture rate on modernised bark playgrounds is concerning and requires further research. (Arch Dis Child 1994; 71: 328-330)
\end{abstract}

Play is vital for children in their physical development and their ability to make social relationships. Although children do play at home and in organised groups, many play in playgrounds provided by local authorities and private organisations. Playgrounds provide an alternative to playing in dangerous places such as the road. However, there is evidence that playgrounds themselves may be dangerous. In South Glamorgan, approximately one in 50 attendances at the accident and emergency department were due to injuries sustained in a playground. ${ }^{1}$ The Leisure Accident Surveillance System which monitors accidents nationwide, estimates that there are 24000 playground injuries each half year in England and Wales. ${ }^{2}$ Illingworth et al studied children with a variety of playground injuries, and found that fractures were three times more common in this group than in the whole group who attended the accident and emergency department. ${ }^{3}$ A few children die each year in playground accidents. ${ }^{4}$

Where accidents to children have been prevented, it has been by making the environment safer rather than by education ${ }^{5}$ and this principle has been applied to playground safety. There has been much work in developing safer equipment and surfaces and in producing acceptable safety standards (BS 5696 and BS 7188). This work has been summarised in Playground Management and Safety by the National Playing Fields Association. ${ }^{6}$ Impact absorbing surfaces have been introduced to lessen the severity of a head injury from falling from equipment onto a hard surface. However, recent criticisms of these surfaces include a lack of proved studies of their effectiveness and their high cost. ${ }^{7}$ We report the results of a study to determine the pattern of public playground injuries presenting to an accident and emergency department from a defined district council area, and to examine safety aspects of playgrounds.

\section{Subjects and methods}

We studied children attending the accident and emergency department in Cardiff Royal Infirmary with an injury occurring in a public playground in the City of Cardiff during two six month periods May-October 1992 and 1993. The Cardiff Royal Infirmary is the only accident department for the City of Cardiff. Accidents at home, school, or in an adventure playground were excluded. Parents of the children completed a questionnaire of accident details with injury description. The main outcome measures were the type of playground equipment and surface, and the description and severity of injury as assessed by the casualty officer.

The details of the equipment and surfaces were ascertained from the City of Cardiff Leisure and Amenities Department. The department has a planned policy of modernisation of playground equipment and surfaces according to need across the city.

The numbers of children attending individual playgrounds were recorded by City of Cardiff playground inspectors during July to October 1993. They counted children playing at individual playgrounds as a snapshot view in time on several occasions. Data on rainy days were excluded.

\section{Results}

EXPOSURE OF CHILDREN TO PLAY INJURIES

The playground inspectors counted 11381 children on 677 visits to 52 bark playgrounds and 21 concrete playgrounds between 31 July and 3 October 1993. There was heterogeneous use of playgrounds (table 1): the premier playgrounds were well used and the playgrounds were more popular in the summer holidays. The pattern of attendance suggested that there were five populations of children playing 
Table 1 Mean number of children observed on the playgrounds

\begin{tabular}{llll}
\hline Playground & Surface & fuly/August 1993 & September/October 1993 \\
\hline Roath Park (P1) & Bark & 86 & $36 \cdot 9$ \\
P2 & Bark & $17 \cdot 6$ & $8 \cdot 4$ \\
P3 & Bark & $18 \cdot 2$ & $11 \cdot 2$ \\
P4 & Bark & $29 \cdot 2$ & $17 \cdot 1$ \\
P5 & Bark & 13 & 11 \\
Bark $(\mathrm{n}=47)$ & Bark & $6 \cdot 4 /$ playground & $4 \cdot 1$ playground \\
P6 & Concrete & $16 \cdot 45$ & $12 \cdot 95$ \\
P7 & Concrete & $14 \cdot 95$ & $3 \cdot 3$ /playground \\
Concrete (n=19) & Concrete & $3 \cdot 5$ /playground & \\
\hline
\end{tabular}

on: (i) one very popular modernised bark premier playground (Roath Park, P1), (ii) four modernised bark popular playgrounds (P2-5), (iii) two unmodernised concrete popular playgrounds (P6 and P7), (iv) 47 less popular bark playgrounds, and (v) 19 less popular concrete playgrounds.

We estimated the average number of children per observational session seen playing on mainly bark surfaces for August to be $464 \cdot 8$ and $275 \cdot 1$ for September/October. Thus the average number of children per observational session on bark for the period of the exposure study was 740 . The corresponding figure for concrete was 187 . These values take account of the larger number of bark play areas to concrete, the larger number of children who play on bark, and the differences observed between separate playgrounds as well as the different rates of play during school holiday and term time. If these figures typify the overall differences between bark and concrete and if the same accident rate holds for bark and concrete, we would expect to have about four times as many accidents on bark as on concrete.

The breakdown of playground equipment on different surfaces shows that $75 \%$ of the pieces of equipment (total number 520) are on the bark surfaces compared with $11 \%$ on concrete, and these items are larger and more modern.

\section{PLAYGROUND INJURIES}

During the study period, a total of 16541 children, aged 0-14 years, attended the Cardiff Royal Infirmary after an injury. One hundred and seventy eight children were injured in public playgrounds; this represents $1 \cdot 1 \%$ of the injured children and $0.3 \%$ of the total child population. Full accident details were obtained for 162 children. The mean age of the children injured in playgrounds was 7.5 years (range $1 \cdot 24-14$ years) and $86(53 \%)$ were males.

One hundred and forty six children (90\%) were injured in relation to equipment of whom $105(65 \%)$ children fell from equipment and $28(17 \%)$ collided with equipment. Fifty three children were injured on a climbing frame, 34 on a slide, 30 on a swing, 15 on monkey bars,

Table 2 Comparison of type of injury and surface

\begin{tabular}{lllllll}
\hline Surface & Laceration & Sprain & Abrasion & Concussion & Fracture & Total \\
\hline Bark & $2(8 \cdot 1)$ & $14(10 \cdot 4)$ & $16(20 \cdot 8)$ & $2(4 \cdot 4)$ & $52(42 \cdot 2)$ & 86 \\
Concrete and tarmac & $9(2 \cdot 8)$ & $0(3 \cdot 6)$ & $12(7 \cdot 2)$ & $4(1 \cdot 6)$ & $5(14 \cdot 7)$ & 30 \\
\hline
\end{tabular}

Figures in brackets are the expected numbers assuming no difference between surfaces. $x^{2}$ on 4 degrees of freedom $=41.03$ giving $p<0.005$. four on a fireman's pole, and others 10 . One hundred and twenty five children had surface related injuries: 86 on modernised bark playgrounds, 30 on concrete/tarmac playgrounds, seven on grass, one on rubber, one on sandy hoggin.

\section{RELATING INJURIES TO EXPOSURE}

Allowing for the difference in exposure, there appear to be fewer injuries on modernised playgrounds than we would expect. Using the estimated fourfold difference, as there were 30 accidents on concrete, we would expect the number on bark to be about 120 . The number observed was 86 . However, on the assumptions described in the appendix, namely that the number of accidents observed follow a Poisson distribution, we find that the difference between 120 and 86 is not statistically significant. There is accordingly a strong indication that there is not a difference in the total accident rate for the two surfaces.

\section{PATTERN OF INJURIES}

Injuries included $64(39.5 \%)$ fractures, 38 abrasions/bruises, 34 lacerations, seven concussion, and 19 sprains. The overall fracture rate for injuries in the same period was $13 \cdot 2 \%$. Twenty eight $(17 \cdot 4 \%)$ children required hospital admission compared with the overall admission rate of $5 \cdot 2 \%$ for all children's injuries over the same period. Of the children who were admitted, 26 (93\%) had a fracture and only one child had a minor head injury and was admitted at parent's request.

There was a significant different pattern of injury on bark and concrete/tarmac surfaces $(\mathrm{p}<0.005$; table 2).

- Fractures and sprains were more frequent on modernised bark playgrounds than on concrete. Fractures accounted for $60 \%$ of the injuries on bark playgrounds and only $17 \%$ on concrete. Of the 52 fractures occurring on bark, 48 were of the upper limb and four the lower limb. The majority of children fell from climbing apparatus (26) or monkey bars (11).

- Lacerations and abrasions occurred less frequently on modernised playgrounds with a $21 \%$ occurrence compared with $70 \%$.

- Although there were only a few cases of concussion, there were fewer on the bark surfaces.

\section{Discussion}

This study has shown that playground injuries account for only a small proportion of injuries to children. However, children injured on public playgrounds have a high hospital admission rate and fracture rate compared with other types of injury. We believe these injuries are best looked upon as being sustained on modernised playgrounds with bark surfaces compared with concrete playgrounds with simple unmodernised equipment as modernisation, in Cardiff, includes updating of equipment as well as surface. 
There was a significant difference in the pattern of injuries. We were encouraged by the small number of head injuries that occurred on bark surfaces, none of which were serious. Bark surfaces were developed to prevent head injury, and they appear to be successful in this. However, we were surprised by the number of children sustaining fractures on bark surfaces: 52 in two summers in Cardiff.

This study attempted to count children playing on playgrounds. Although this is only a snapshot view, it confirmed our impression that more children play on the modernised playgrounds. Comparison of total injury rates, allowing for the difference in exposure, showed there were fewer injuries on modernised playgrounds than we would expect but these differences were not significant.

There are many possible variables in playground injuries:

- Type of equipment

- Type of surface

- Height of equipment

- Number of children playing

- Type of play of the children

- Maintenance of the surface

- Maintenance of the equipment

- Weather

- Supervision.

We believe that many of these factors are interlinked and difficult to interpret. We were concerned by the high fracture rate on modernised playgrounds. There is some evidence from work in New Zealand ${ }^{8}$ that height of equipment may be one of the important variables and it may be that bark is not protective against arm fracture in heights above 2 metres. Monkey bars were only separately identified in the study in 1993. The number of injuries on monkey bars is therefore an underestimate; however, injuries on monkey bars were more severe: seven children from 15 injured were admitted. The safety of monkey bars will need to be looked at critically in future.

We had no evidence that maintenance of surfaces was a factor in injuries in Cardiff. Bark surfaces need regular maintenance to retain impact absorbing properties. Further research relating bark depth and impact absorption to injuries is needed. Children may take more risks on bark surface. It is also likely that because the play equipment is more interesting the patterns of play are different.

We emphasise that the provision of proper playground facilities is vital for children both for their development and safety. The majority of deaths from accidents in children are pedestrian road traffic injuries. Children are much safer playing in a public playground than on the road. We believe that modernising playgrounds is likely to have reduced head injuries, lacerations, and abrasions and certainly has provided good play opportunities for children. This study should not be used as a basis for not modernising playgrounds but for looking critically at the design of equipment, particularly high climbing frames and monkey bars, on bark surfaces.

Further studies are needed to describe the risks of playground injuries with individual play surfaces and equipment. This should include rubberised surfaces and link these with the exposure of children playing at playgrounds and the height of equipment.

We thank the Leisure and Amenities Department of the Cardiff City Council for all their information, help, and encouragement.

\section{Appendix}

Take $\mathrm{p}$ to be the probability of an accident to a single child and $\mathrm{n}$ to be the total number of children playing on concrete over the time relating to the accidents which were recorded. On our assumptions the number of accidents $\left(a_{c}\right)$ expected on concrete would be $\mathrm{np}$ and those $\left(a_{b}\right)$ on bark would be $4 \mathrm{np}$. Do the figures of 30 for $a_{c}$ and 86 for $a_{b}$ indicate $a$ real difference between the accident rates on concrete and bark?

When, as in this case, $p$ is small and $n$ is large the difference $\left(4 a_{c}-a_{b}\right)$ has mean zero and standard deviation $0.2 \sqrt{5 n p}$. The sum $\left(a_{c}+a_{b}\right)$ has mean 5np. If the accidents observed are near to those expected we can take this sum as an estimate of $5 \mathrm{np}$. We therefore find that $\sqrt{5 n p}$ is about 10.8 so that the difference $\left(4 a_{c}-a_{b}\right)$ has standard deviation of around $21 \cdot 6$. Thus, the observed value of this difference, namely 34, is only 1.6 times its standard deviation. This is accordingly an indication that the difference observed in the injuries overall has little or no significance.

1 Sibert JR, Maddocks GB, Brown M. Childhood accidents an endemic of epidemic proportions. Arch Dis Child 1981 56: 225-7.

2 MacCleary L. Playgrounds - leisure accident surveillance system (LASS). London: Consumer Safety Unit Department of Trade and Industry, 1989.

3 Illingworth C, Brennan P, Jay A, Al-Rawi F, Collick M. 200 Injuries caused by playground equipment. $B M F$ 1975; iv: 332-4

4 Nixon J, Pearn J, Wilkey I. Death during play; a study of playground and recreation deaths in children. $B M \mathcal{F} 1981$; playground

5 Sibert JR. Accidents to children: the doctor's role education or environmental change. Arch Dis Child 1991; 66: 890-4. 6 Heseltine P, Holborn J, Wenger J. Playground management and safety. London: National Playing Fields Association,

7 Ball D, King K. Playground injuries: a scientific appraisal of popular concerns. $\mathcal{F} R$ Soc Health 1991; August: 134-7. 8 Chalmers DJ, Langley JD. Epidemiology of playground equipment injuries resulting in hospitalisation. $\mathscr{f}$ Paediat Child Health 1990; 26: 329-34. 